\title{
Guidelines for Taking Care of the Quality of Life of People in the Local Area to Support Aging Society in Thailand
}

\author{
Chanit Suntapun
}

\begin{abstract}
The economic development of the world makes the population increased income. Living standards have improved with the advancement in Medicalization which will improve population to be healthier. The mortality rate decreased. The average life expectancy increased. Thus, the world can not avoid stepping into the aging society. So, It affects the appearance of social and economic dependency between various age population. There are seniors who need to lean on labor-age more. Such circumstances above directly impact the role of government officer changes in care and quality of life which has extensive scope than just health. It leads to the adjustment of spatial management role and determine the roles of relevant sectors as well as creating community health system to accommodate the changes, that is, local government agencies, which is close to most people because of the election of the people in the area. So, there is a need to prepare for those changes.
\end{abstract}

Keywords - An aging society, Medicalization, Quality of life, Local government agencies, the quality of life in district level.

\section{INTRODUCTION}

The economic development of the world community makes the population increased income. Living standards have improved with the advancement in Medicalization which will improve population to be healthier. The mortality rate decreased. The average life expectancy increased. Thus, the world cannot avoid stepping into the aging society. According to the United Nations World Population Ageing found that after B.E. 2552 the population is in age dependency include children and the elderly which has the amount of working age population. In the year 2560 will be the first time in the history of the population of children that less than the elderly. In Thailand National Statistical Office concluded that Thailand is moving into an aging society since B.E. 2548 with the elderly population 10.4 percentage of all population in Thailand and expected to be complete by entering an aging society around B.E. 2567-2568. The effect in both economic and social that happen from the aging society is when there are more elderly people that will affect the structure of working age and dependency age. That is, the ratio of the age dependence population is higher than working age population. Saving is decreasing because of less income ratio. The government must have the expenditure on social welfare and medical treatment

Chanit Suntapun, National Institute of Development Administration Thailand increased [1]. Therefore, it is necessary to change the role of the public sector to support the management of healthcare and welfare provided to elderly and leads to the issues of the research study to the spatial management role and determines the role of relevant sectors as well as creating community health system to support the changes.

\section{PROBLEMS OF THAI BUREAUCRACY}

The chronic problems in the bureaucracy system of Thailand that affect the management of public health. There are several reasons, including separation of duties under the scope of the mission of each agency both the central government, provincial and local governments and affect the problem of lacking efficiency in the management of health, such as the case of local government. Data from the literature review, in-depth interviews and focus group discussion, the result found the consistent data. Local government alone does not have the potential to be a public health care in the area fully. Due to the lack of knowledge and expertise in medical and public health, budget, facilities, shortages of doctor and public health personnel as well as modern medical equipment.

The operation through the local government in the past, it was very difficult and couldn't take care of the people as well as they should receive. With the management of the health system is in a "fragmented" The gap in terms of resource management and service to the people, also the team of healthcare providers that was a unique group, lack of diversity. So, not all of the people can access health care services as well as the diverse situation and more complex. And the structure of the population is stepping into the aging society. Factors threatening the health and disease of the people are more likely chronic non-communicable diseases. As a result, the health services in the original format cannot meet the needs of individuals and communities throughout and equitable due to the health care service that has the crowded patient at the large hospital which is still not enough to meet demand in the area. In addition to the financials mechanism, there is a disparity between the funds and the lack of a mechanism that improves the potential of the financial of the health care system as a mechanism to save and use the data as a whole both public and private sectors still weak, lack of information systems for monitoring the prevention of diseases and health threats which directly affects the quality of health services in areas of public 
life sustainable.

\section{SOLUTION FOR HEALTH SYSTEM}

Reformation health system of the country is necessary to reform the health system in terms of the healthcare service system to focus on providing services in Primary Care Cluster (PCC) [2] to be a link between the community and Hospital service with seamless. Also, the development of health promotion system and disease prevention with strength by integrating the cooperation of all sectors whether the government, including provincial governors, which has strengths in terms of budget, personnel and knowledge. Local governments which have strengths in terms of being closely linked to people in the area. Including the private sector which represented interest groups and civil society to open space in participation to people in each area in order to monitor together about health services at the local level to respond to a public health problem in the area effectively.

For this reason, the Ministry of Interior, Ministry of Public Health, National Health Security Office and Thai Health Promotion Foundation. Therefore, they get together to push for District Health Board as a "solution" of the problem under the framework "The area is a base People-centered", with the idea that the establishment of a committee to integrate the work of many sectors of the central, regional and local. It is one way to help succeed the mission of public health rather than separation or transfer tasks to local governments manage themselves alone without the support of knowledge, personnel and budget. In addition, the district also has the scale suitable to be a "host" or centered on the management of health due to the regional administration is closer to the people moderately. Moreover, the role of central government authority lessens compared to the provincial areas of responsibility, which was not too close to the people as it should as well as the provincial governor and the head of government sector of the provincial governor, who receives orders directly from the center. As a result, the image of the province is closely linked to the center quite a lot and has the role of representing the community and the area is rather small. While the district will have an atmosphere of participation from the public sector more and reflecting a sense of community ownership of public space more. District or village is too small. There isn't the potential to be a public service, which requires knowledge and advanced techniques to the public health by themselves.

Later, it was promulgated "Regulations of the Office of the Prime Minister to improve the quality of life of the area level B.E. 2561" was held on March 9 B.E. 2561 with the intention to drive and improve the quality of life for people in the area level. As to the strategic direction and targets in a systematic and effective by the integration of corporation between government sector, the private sector and civil society as a whole. Also, focus on the involvement of all sectors in the areas of people-centered. Strengthening leadership and ownership in the development and resolve problems in the area as well as strengthening the personnel, family and community health to have physical, mental and social well being and sustainable in the future.

\section{ANALYSIS OF DisTRICT HEALTH BOARD}

considering the regulations of the Prime Minister on the quality of life of the area level in 2561 and found that regulations have created a platform for the "integration" of management. "Quality of Life" which includes everything about the lifestyle of the people, health, education, the environment, social security, caring for the disadvantaged etc. in areas, The structure of the District Health Board. It consists of

1. Representatives of state agencies in the district include sub district headman, village headman, local government.

2. Representatives of the private sector in the district by selection of professional medical and public health, the entrepreneur in health or public health, private School, Professional or other business.

3. Representatives of the public sector in the district by selecting from those who have knowledge of or experience with social development or local community or local wisdom, networking groups or private nonprofit organizations or a network of volunteers who work in the district. The public health district is the Director and Secretary.

This committee will play a key role in determination plan, goals and strategy to improve the quality of life in the district by integrating and mobilizing the resources available in the district both from the government sectors, private sectors and public sectors in order to drive to achieve the plan goals and direction and strategy to improve the quality of life in the district as well as support and encourage local communities to participate in managing the health of local people.

However, considering the structure of the development of the district level committee which plays the role of government region clearly. On the other hand, local governments play a role as the only supporter. This is because health care management needs to rely on the techniques of knowledge academic medicine and public health but local government lack of both Human resources and budget to develop knowledge in this field. The analysis of the intention of the establishment of this committee that the state didn't want local governments to take responsibility to build expertise in care and treatment but want local governments to play a role as "The owner of the area" that is, who won the election process from the people in the area which is very close to the people. The relationship with the people in the horizontal and know the needs of the people and the regional government which has a relationship with people in the vertical or "parent" another strength of local government is being a coordinator, pull the cooperation from all sectors. Integrated according to their aptitude and potential of each agency by having "community" or "area" as the base and the people are the center.

\section{V.SUGGESTION}

So the author has suggested that the role of local 
government in the future is not creating specific expertise in techniques but to act as "coordination unit" or "unit support" especially the information to the development of the district level committee and primary care unit or team doctor family because local governments will access to basic health of the local population better than government region. In addition, the role of local should host a major operator in the care of the elderly in the area by providing the social welfare care for the elderly which is not a job that requires technical expertise but relies on the cooperation of many sectors including administration, social development, education, labor, culture, tourism and sports, such as creating care centers for elderly, providing informal education, Training career, Job creation in the area, create sporting and recreational facilities, visiting the elderly at home and so on.

\section{CONCLUSION}

Summary the guidelines for the establishment of the "District Health Board" as well as the implementation of policies for managing the health of the people in the area with a focus on public health proactive or "create before repair" through "Primary Care Cluster" is the "answer" to reform the health system in Thailand in a satisfactory level. But at the same time, it is a challenge to watch that. Implementation of the next phase after the promulgation of the regulations of the Prime Minister on the quality of life of the area in 2561 and then to solve problems and create a system of care, quality of life can be sustained much.

\section{REFERENCES}

[1] Sukhothai Thammathirat Open University, Aging Society : an Indication Economic Development, retrieved on July 9,2017 from http://www.stou.ac.th/stouonline/lom/data/sec/Lom12/05-01.html.

[2] Working Group for Service Reform, Guideline for Primary Care Cluster. Bangkok: Ministry of Public Health, 2017, pp. 1-2.

[3] Office of Strategic Management, Ministry of Public Health, Guideline for District Health Board. Bangkok: Ministry of Public Health, 2016, pp. 1-2. 